\title{
New Permeation Model for Mixed Matrix Membrane with Porous Particles
}

\author{
Zahra Sadeghi, Mohammad Reza Omidkhah, and Mir Esmaeil Masoumi
}

\begin{abstract}
In the present work, existing permeation models for mixed matrix membranes (MMMs) are introduced in two categories. A new permeation model is proposed based on thermal effective conductivity of composite polymers filled with particles. Relative permeability of polymer to particle in two phase models modified with considering interface layer effect through relative permeability of particle to interfacial layer. The predicted permeability of the new developed model was validated with comparing different experimental data and existing models.
\end{abstract}

Index Terms - Gas permeation, mixed matrix membrane, modeling, porous particles.

\section{INTRODUCTION}

In the past few years, membrane-based process often is preferred to be used for gas separation process [1]. The main membrane-based separations are $\mathrm{H}_{2} / \mathrm{CO}_{2}$ separation for hydrogen production in fuel cells, $\mathrm{CO}_{2} / \mathrm{N}_{2}$ separation in flue gas or lime oven exhaust gases, $\mathrm{CO}_{2} / \mathrm{CH}_{4}$ separation for natural gas treatment or for biogas upgrading, and $\mathrm{O}_{2} / \mathrm{N}_{2}$ separation for production oxygen enriched air or pure nitrogen [2].

Membranes are categorized based on their structure, material, modules, which indicate that material category is important. Membranes are fabricated by different materials such as polymer, ceramic, carbon, metal, and liquid. However, polymeric membranes are very competitive in performance and economics; therefore, they are the most common type of the membranes. Polymeric Membranes usually are used for separation processes in medical, technical and pharmaceutical applications such as; haemodialysis, water treatment, beverage and food industry, the most common polymers in membrane synthesis are cellulose acetate, Nitrocellulose, and cellulose esters (CA, $\mathrm{CN}$, and $\mathrm{CE}$ ), poly sulfone (PS), poly ether sulfone (PES), poly acrilo nitrile (PAN), polyamide, polyimide, polyethylene and polypropylene (PE and $\mathrm{PP}$ ), poly tetra fluoro-ethylene (PTFE), polyvinylidene fluoride (PVDF), polyvinylchloride (PVC) [3], [4].

In this paper, first, MMMs and their main existing permeation models are reviewed. Then with introducing permeation model of effective thermal conductivity of Singh,

Manuscript received September 4, 2014; revised December 17, 2014.

Z. Sadeghi and M. E. Masoumi are with the Chemical Engineering Department, Islamic Azad University-Tehran North Branch, Tehran, P.O.Box.1667934783, Iran (e-mail: zahrasadeghi58@gmail.com, m_masoumi@iau-tnb.ac.ir).

M. R. Omidkhah was with the UMIST, Manchester, UK. He is now with the Department of Chemical Engineering, Tarbiy at Modarres University, Tehran, P.O.Box 14115-143, Iran (e-mail: omidkhah@modares.ac.ir). a new three-phase model by considering interfacial layer between polymer phase and particle phase in mixed matrix membranes was developed The results of the calculated gas permeability were compared with experimental data, and existing models in different MMMs using MATLAB software.

\section{MiXed MATRIX MEMBRANE}

The latest membrane morphology is Mixed Matrix Membranes (MMMs). MMMs are combined of organic polymer and inorganic fillers for separation. The continuous phase is typically a polymer and the dispersed phase consists of inorganic particles; such as zeolite, activated carbon, silica, carbon molecular sieves, nano-size particles and Metal Organic Frameworks (MOFs). MMMs have intrinsic potential to attain higher selectivity and permeability in contrast with pure polymeric membranes, because of inserting inorganic particles with their inherent superior separation characteristics. Indeed, MMMs have a better result in gas separation owing to incorporation of molecular sieves in organic polymers [5], [6]. The characteristics of polymeric membranes demonstrated in Fig. 1. Robesson graphs show the place of polymeric membranes in the best trade-off selectivity and permeability in 1998. Later he updated his researches in 2008And in the recent graphic is obvious that the MMM approach surpassed upper bound behavior [7], [8].

The MMM, generally are fabricated in four main steps;

Firstly, Preparation of membrane materials; polymer solution and pre-treatment of inorganic filler, then, mixing polymer, solution, and filler, next, Casting these mixture to a support structure and finally, drying of prepared MMMs as a post-treatment step, respectively [9], [10].
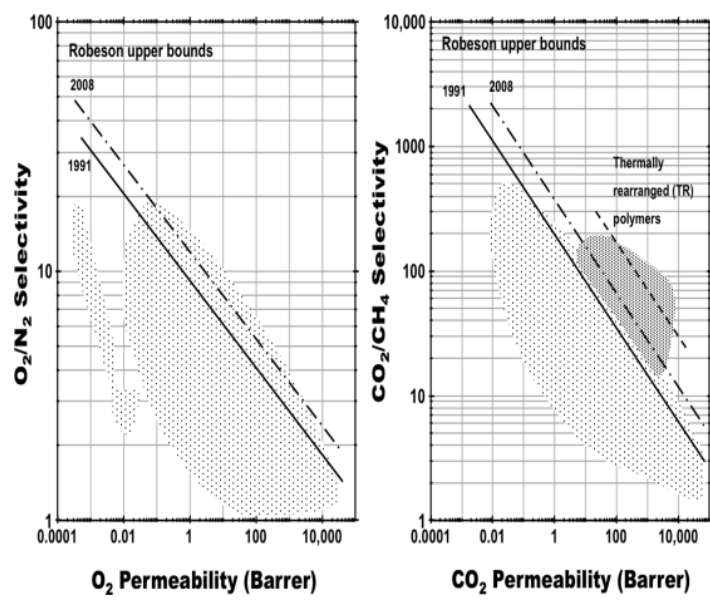

Fig. 1. Robesson graphs for separation $\mathrm{O}_{2} / \mathrm{N}_{2}$ and $\mathrm{CO}_{2} / \mathrm{CH}_{4}$ in membranes [8]. 
The surface contact between polymer and inorganic fillers is the main indicator of separation performance in MMMs. If an ideal contact without any defects between polymer and particle happens, separation rate of gas is highly perceptible. On the other hand, if some defects appear in the surface contact between polymer and particles, during the fabrication, the rate of gas separation will decrease through MMMs.

TABLE I: SUMMARY OF MAIN EXISTING PERMEATION MODELS FOR MMMS [2], [11]-[24]

\begin{tabular}{|c|c|c|}
\hline Authors & $\frac{\mathscr{D}}{E}$ & Model \\
\hline Maxwell & 2 & $P_{r}=\frac{1+2 \phi\left(\lambda_{d m}-1\right) /\left(\lambda_{d m}+2\right)}{1-\phi\left(\lambda_{d m}-1\right) /\left(\lambda_{d m}+2\right)}$ \\
\hline Bruggeman & 2 & $P_{r}^{\frac{1}{3}}\left(\frac{\lambda_{d m}-1}{\lambda_{d m}-P_{r}}\right)=(1-\phi)^{-1}$ \\
\hline $\begin{array}{l}\text { Lewis- } \\
\text { Nielsen }\end{array}$ & 2 & $P_{r}=\frac{1+2 \phi\left(\lambda_{d m}-1\right) /\left(\lambda_{d m}+2\right)}{1-\phi \psi\left(\lambda_{d m}-1\right) /\left(\lambda_{d m}+2\right)}$ \\
\hline Pal & 2 & $\left(\frac{P_{e f f}}{P_{c}}\right)^{1 / 3}\left[\frac{\left(\frac{P_{d}}{P_{c}}\right)-1}{\left(\frac{P_{d}}{P_{c}}\right)-\left(\frac{P_{e f f}}{P_{c}}\right)}\right]=\left(1-\frac{\phi}{\phi_{m}}\right)^{-\phi_{m}}$ \\
\hline Bottcher & 2 & $\left(1-\frac{P_{c}}{P_{e f f}}\right)\left(a+2 \frac{P_{e f f}}{P_{c}}\right)=3 \phi(a-1)$ \\
\hline $\begin{array}{l}\text { Chiew and } \\
\text { Glandts }\end{array}$ & 2 & $\frac{P_{e f f}}{P_{C}}=1+3 \beta \phi+K \phi^{2}+O\left(\phi^{3}\right)$ \\
\hline $\begin{array}{l}\text { Modified } \\
\text { Maxwell }\end{array}$ & 3 & $\begin{array}{l}P_{r}=\frac{P}{P_{m}}=\left[\frac{2(1-\phi)+(1+2 \phi) \frac{P_{e f f}}{P_{m}}}{(2+\phi)+(1-\phi) \frac{P_{e f f}}{P_{m}}}\right. \\
P_{\text {eff }}=P_{i}\left[\frac{2\left(1-\phi_{s}\right)+\left(1+2 \phi_{s}\right) \frac{P_{d}}{P_{i}}}{\left(2+\phi_{s}\right)+\left(1-\phi_{s}\right) \frac{P_{d}}{P_{i}}}\right.\end{array}$ \\
\hline Felske & 3 & $P_{r}=\frac{P}{P_{m}}=\left[\frac{2(1-\phi)+(1+2 \phi) \frac{\beta}{\gamma}}{(2+\phi)+(1-\phi) \frac{\beta}{\gamma}}\right]$ \\
\hline $\begin{array}{l}\text { Modified } \\
\text { Felske }\end{array}$ & 3 & $P_{r}=\frac{1+2 \phi(\beta-\gamma) /(\beta+2 \gamma)}{1-\psi \phi(\beta-\gamma) /(\beta+2 \gamma)}$ \\
\hline $\begin{array}{l}\text { Modified } \\
\text { Pal }\end{array}$ & 3 & $\begin{array}{r}\left(\frac{P_{e f f *}}{P_{m}}\right)^{1 / 3}\left[\frac{\lambda_{d l}-1}{\lambda_{d l}-\left(\frac{P_{e f f *}}{P_{i}}\right)}\right]=\left(1-\frac{\phi_{s}}{\phi_{m}}\right)^{-\phi_{-}} \\
P_{r}{ }^{1 / 3}\left[\frac{\lambda_{\text {eff } * m}-1}{\lambda_{\text {eff } *_{m}}-\left(P_{r}\right)}\right]=\left(1-\frac{\phi_{z}}{\phi_{m}}\right)^{-\phi_{m}}\end{array}$ \\
\hline
\end{tabular}

Some researchers believe that a poor adhesion between polymer and inorganic filler makes different defects. Therefore, it was assumed to create an interfacial layer between polymer matrix and dispersed phase. Formation of a rigidified polymer layer around inorganic fillers, pore blockage in porous particles or creation of voids between polymer and particle are the main reasons to make an interfacial layer phase [2], [11]-[17].

Substantially, one of the major difficulties experienced in preparation of MMMs is pore blockage of inorganic fillers by the polymer chains which leads to low selectivity and blockage of the pores by polymer chains. This may completely eliminate the function of porosity of porous fillers [3]. Basically, proposed Mathematical modeling for MMMs categorized based on two different morphologies which will be discussed in next section.

\section{EXISTING PERMEATION MODELS}

According to the of literature [2], [11]-[24], there are many permeation models for MMMs. Preliminary models are based on ideal morphology between polymer and dispersed phase which is obtained originally of predicted thermal or electrical conductivity models. The main models categorized in two groups which are two-phase (particle-polymer) and three-phase (particle-interfacial layer-polymer). The models which were considered are Maxwell, Bruggeman, Lewis-Nielsen, Pal, Chiew-Galandt, Bottcher, Higuchi, Felske, modified Maxwell, Modified Felske and modified Pal. The main and important permeation models for MMMs are summarized and reported by morphology categorization in Table I.

\section{NEW PROPOSED MOdEL}

A new expression for effective thermal conductivity (ETC) of polymer composites has been developed by Singh. In this expression, a cylindrical lattice structure with regular distribution of spheres is considered. The Green's function solution of Poisson's equation was used for dispersion in flux modifications. In this model, with incorporation of different geometries of particles and considering non-leaner flow of heat flux lines which generated by the difference in thermal conductivities of constituent phases, Singh illustrates a correlation term in place of physical porosity and thermal conductivity function which has been solved with the help of Green's function method, Gauss's theorem [26].

The Singh thermal conductivity model, with replacing thermal conductivity by permeability, is reported as below:

$$
\begin{gathered}
P_{r}=1+3.74\left(\frac{\lambda_{d m}-1}{\lambda_{d m}+2}\right) * \phi^{2 / 3} \\
\lambda_{d m}=\frac{P_{d}}{P_{m}}
\end{gathered}
$$

This equation expresses a two-phase model to predict permeability of MMMs. In this paper, with considering presence of interfacial layer in the surface contact of polymer and particle, a new three-phase model is proposed based on Singh model.

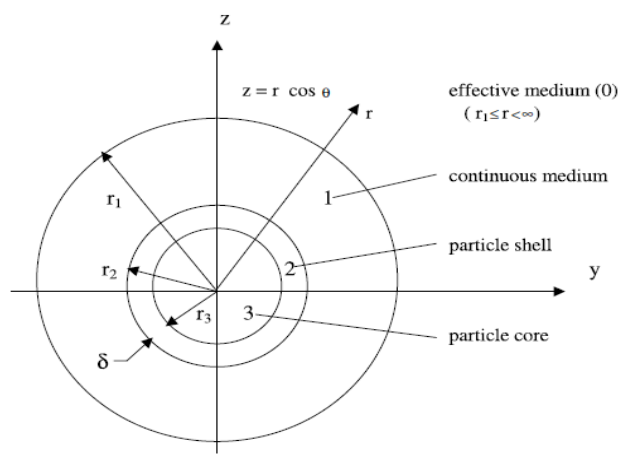

Fig. 2. Schematic of considering three phase in Felske model [24]. 
According to felske (a three-phase model), effective permeability is calculated with relative permeability in three phases, which are particle to polymeric matrix $\left(\lambda_{d m}\right)$, particle to interfacial layer $\left(\lambda_{d i}\right)$ and interfacial layer to polymeric matrix $\left(\lambda_{i m}\right)$, respectively (Fig. 2). Felske simplified his model with obtaining $\beta$ and $\gamma$ parameters which have been defined with relative permeability of three phases [25].

$$
\begin{gathered}
\lambda_{d i}=\frac{P_{d}}{P_{i}} \\
\lambda_{i m}=\frac{P_{i}}{P_{m}} \\
\beta=\left(2+\delta^{3}\right) \lambda_{d m}-2\left(1-\delta^{3}\right) \lambda_{i m} \\
\gamma=1+2 \delta^{3}-\left(1-\delta^{3}\right) \lambda_{d i}
\end{gathered}
$$

With comparing Maxwell model (two-phase) and Felske model (three-phase),it seems the relative permeability, $\lambda_{d m}$, has been replaced by expression $\beta / \gamma$. If this is a tight assumption, all two-phase models are capable to be changed in three-phase model by this displacement. To prove this concept, firstly, it is assumed that expression $\beta / \gamma$ is equal to $\lambda_{d m}$, then, with expanding relative permeability definition in the both side of the Eq. (7) and simplifying the mathematical functions, an accurate expression is achieved. Therefore, the validity of this assumption is resulted.

Firstly:

$$
\begin{gathered}
\lambda_{d m}=\frac{\beta}{\gamma} \\
\lambda_{d m}=\frac{\left[\left(2+\delta^{3}\right) \lambda_{d m}-2\left(1-\delta^{3}\right) \lambda_{i m}\right.}{\left[1+2 \delta^{3}-\left(1-\delta^{3}\right) \lambda_{d i}\right]}
\end{gathered}
$$

These two correlations expanded as below:

$$
\frac{P_{d}}{P_{m}}=\frac{\left[\left(2+\delta^{3}\right) \frac{P_{d}}{P_{m}}-2\left(1-\delta^{3}\right) \frac{P_{i}}{P_{m}}\right]}{\left[1+2 \delta^{3}-\left(1-\delta^{3}\right) \frac{P_{d}}{P_{i}}\right]}
$$

Assumption: interfacial layer is absent in two phases model, therefore $\delta$ is equal to zero, and the expression is simplified as below:

$$
\begin{gathered}
\frac{P_{d}}{P_{m}}=\frac{\left[2 \frac{P_{d}}{P_{m}}-2 \frac{P_{i}}{P_{m}}\right]}{\left[1-\frac{P_{d}}{P_{i}}\right]} \\
\frac{P_{d}}{P_{m}}=\frac{\left[\frac{P_{d} \cdot P_{i}}{P_{m}}-2 \frac{P_{i}^{2}}{P_{m}}\right]}{\left[1-\frac{P_{d}}{P_{i}}\right]}
\end{gathered}
$$

$$
\begin{gathered}
P_{d}\left(P_{i}-P_{d}\right)=2 P_{i}\left(P_{d}-P_{i}\right) \\
P_{d} P_{i}-P_{d}^{2}=2 P_{d} P_{i}-2 P_{i}^{2} \\
2 P_{i}^{2}-P_{d} P_{i}-P_{d}^{2}=0
\end{gathered}
$$

Precisely, this equation has two solutions,, so that, first answer is negative and unreasonable and second answer is acceptable, as a result. Therefore, Eq. (7) is evaluated correctly and $\lambda_{d m}$ in two-phase model can be replaced by $\beta / \gamma$

\begin{tabular}{|c|c|c|c|c|c|c|}
\hline$\sum_{\sum}$ & 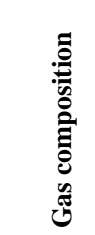 & 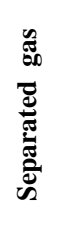 & 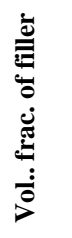 & 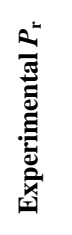 & $\frac{\overbrace{}^{2}}{\frac{\tilde{d}}{\pi}}$ & 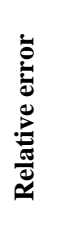 \\
\hline \multirow{4}{*}{ 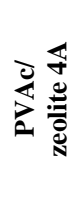 } & \multirow{4}{*}{$\mathrm{O}_{2} / \mathrm{N}_{2}$} & \multirow{4}{*}{$\mathrm{O}_{2}$} & 0 & 1.00 & 1.00 & 0 \\
\hline & & & 0.15 & 0.90 & 0.83 & 7.92 \\
\hline & & & 0.25 & 0.80 & 0.76 & 5.08 \\
\hline & & & 0.40 & 0.70 & 0.67 & 4.18 \\
\hline \multirow{5}{*}{ 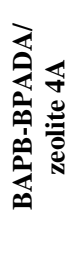 } & \multirow{5}{*}{$\mathrm{O}_{2} / \mathrm{N}_{2}$} & \multirow{5}{*}{$\mathrm{O}_{2}$} & 0 & 1.00 & 1.00 & 0 \\
\hline & & & 0.15 & 1.00 & 0.87 & 13.1 \\
\hline & & & 0.20 & 0.94 & 0.84 & 10.6 \\
\hline & & & 0.30 & 0.80 & 0.79 & 1.13 \\
\hline & & & 0.40 & 0.74 & 0.75 & 0.90 \\
\hline \multirow{4}{*}{ 疍 } & \multirow{4}{*}{$\mathrm{O}_{2} / \mathrm{N}_{2}$} & \multirow{4}{*}{$\mathrm{O}_{2}$} & 0 & 1.00 & 1.00 & 0 \\
\hline & & & 0.19 & 1.13 & 1.2 & 6.16 \\
\hline & & & 0.33 & 1.3 & 1.29 & 0.88 \\
\hline & & & 0.36 & 1.42 & 1.31 & 8.04 \\
\hline \multirow{5}{*}{ 离 } & \multirow{5}{*}{$\begin{array}{l}\mathrm{CO}_{2} / \\
\mathrm{CH}_{4}\end{array}$} & \multirow{5}{*}{$\mathrm{CO}_{2}$} & 0 & 1.00 & 1.00 & 0 \\
\hline & & & 0.17 & 1.03 & 1.10 & 6.86 \\
\hline & & & 0.19 & 1.06 & 1.08 & 4.56 \\
\hline & & & 0.33 & 1.15 & 1.16 & 0.57 \\
\hline & & & 0.36 & 1.26 & 1.17 & 7.46 \\
\hline
\end{tabular}
to change to three-phase model. According to this result, it is obvious that new Singh developed model of two-phase model is achieved by this formula:

$$
P_{r}=1+3.74\left(\frac{\frac{\beta}{\gamma}-1}{\frac{\beta}{\gamma}+2}\right) * \phi^{2 / 3}
$$

Accuracy of gas relative permeability in the new proposed model is evaluated by Matlab software with the experimental data. In addition, it is compared with other existing models of MMMs listed in Table II.

TABLE II: Calculation of Relative Gas PeRmeability in NeW PROPOSED MODEL AND EXPERIMENTAL DATA IN FOUR MMMs 


\section{RESUlt DisCUSSION}

\section{A. New Model Compared with Experimental Data in Different MMMs}

Calculation of gas relative permeability in new proposed model by comparing with the experimental permeability at different loading of inorganic particles shows that estimated permeability is close to real system and gas transport behavior through MMMs predicts accurately. This phenomenon is observed well in the mentioned MMMs in the bar chart (Fig. 3).

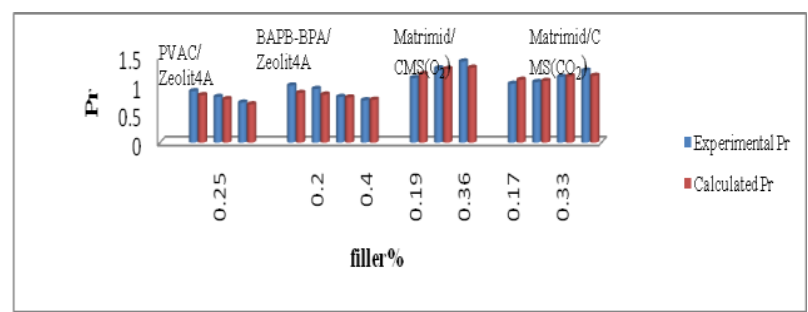

Fig. 3. Comparison of relative gas permeability in new model and experimental data in four MMMs.

\section{B. Comparison Between Existing Models and New Model in Different MMMs}

In this paper, the new proposed model is checked against other existing models for MMMs. Estimated relative permeability in existing models and new proposed model compared with experimental data by least square error in four mentioned MMMs. Results of least square errors are summarized in Table III.

As can be seen in Table III, the size of the error in two-phase models is absolutely higher than three-phase models. Therefore, it can be concluded that gas permeability in three-phase models is anticipated better than two-phase models in MMMs. To more illustrate this concept, the obtained results from Matlab are compared in Fig. 4- Fig. 11.

TABLE III: COMPARISON LEAST SQUARE ERROR OF NEW PROPOSED MODEL WITH EXISTING MODELS IN FOUR MMMS

\begin{tabular}{|c|c|c|c|c|}
\hline \multicolumn{4}{|c|}{ WITH EXISTING INODELS IN FUUR MININIS } & \\
\hline 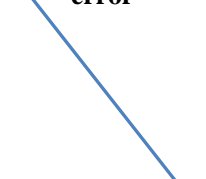 & $\begin{array}{c}\text { PVAC/ } \\
\text { Zeolit4 } \\
\left(\mathrm{O}_{2}\right) \mathbf{A}\end{array}$ & $\begin{array}{c}\text { BAPD- } \\
\text { DAAPD } \\
\text { /Zeolit4 } \\
\text { A } \\
\left(\mathbf{O}_{2}\right)\end{array}$ & $\begin{array}{c}\text { Matrimid } \\
\text { /CMS } \\
\left(\mathrm{O}_{2}\right)\end{array}$ & $\begin{array}{c}\text { Matrimi } \\
\text { d/CMS } \\
\left(\mathrm{O}_{2}\right)\end{array}$ \\
\hline \multicolumn{5}{|c|}{2 PHASE } \\
\hline Maxwell & 0.38 & 0.35 & 0.59 & 1.13 \\
\hline Lewis & 0.41 & 0.39 & 0.87 & 1.99 \\
\hline Bruggeman & 0.38 & 0.36 & 0.71 & 1.91 \\
\hline Pal & 0.42 & 0.4 & 1.04 & 3.14 \\
\hline Chiew-Galandt & 0.27 & 0.24 & 0.12 & 0.22 \\
\hline Bottcher & 0.38 & 0.36 & 0.87 & 3.52 \\
\hline Higuchi & 0.45 & 0.43 & 1.69 & 7.82 \\
\hline \multicolumn{5}{|c|}{3 PHASE } \\
\hline $\begin{array}{l}\text { Modified } \\
\text { Maxwell }\end{array}$ & 0 & 0.02 & 0.01 & 0.01 \\
\hline Felske & 0.02 & 0.03 & 0.03 & 0.07 \\
\hline Modified Felske & 0.02 & 0.02 & 0.03 & 0.06 \\
\hline Modified Pal & 0.28 & 0.25 & 0.3 & 0.69 \\
\hline New proposed & 0.01 & 0.03 & 0.02 & 0.02 \\
\hline
\end{tabular}

In Fig. 4, the estimated relative permeability of $\mathrm{O}_{2}$ has been indicated against different filler loadings in MMM made of PVAC/Zeolit4A. It can be seen that new proposed model (new3 in graph) predicts the gas permeability as well as the modified Maxwell model. Moreover, this results clearly shown in Fig. 5 by comparing least square error of all the models.

In Fig. 6-Fig. 11, the same consequences are seen in MMMs fabricated with BAPB-BPADA /Zeolit4A for separation $\mathrm{O}_{2} / \mathrm{N}_{2}$, Matrimid $/ \mathrm{CMS}$ for separation $\mathrm{O}_{2} / \mathrm{N}_{2}$, Matrimid /CMS for separation $\mathrm{CO}_{2} / \mathrm{CH}_{4}$, respectively.In all four samples, new proposed model anticipates gas behavior as well as modified Maxwell and better than other existing models.

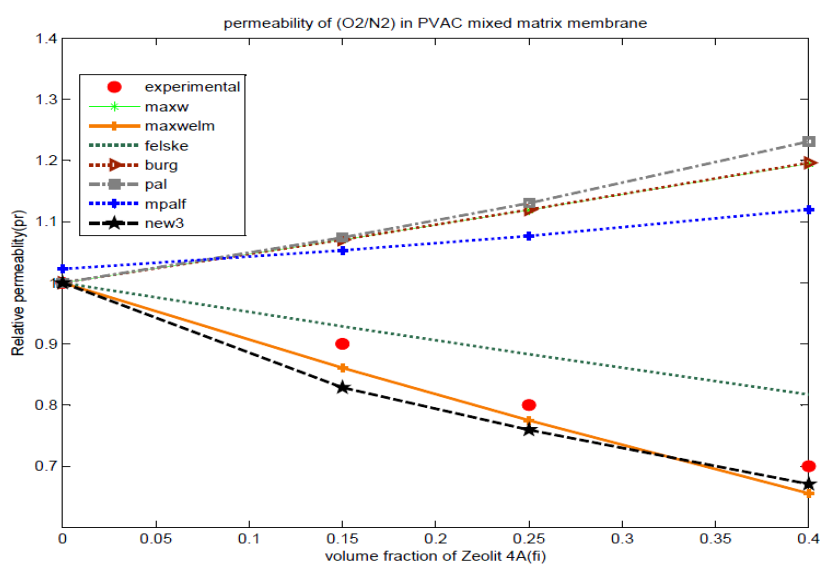

Fig. 4. Comparison of relative permeability of new model with existing models in system PVAC/Zeolit4Afor separation $\mathrm{O}_{2} / \mathrm{N}_{2}$.

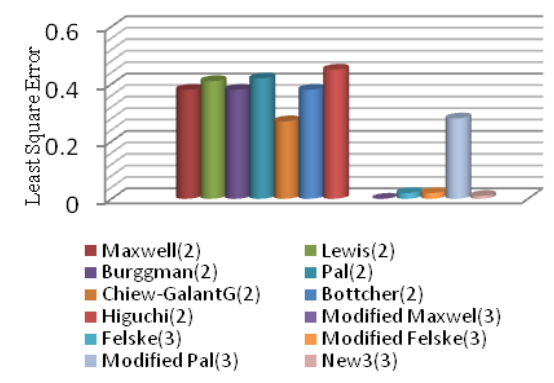

Fig. 5. Comparison between least square error of new proposed model with exising models of PVAC/Zeolit4A system for separation $\mathrm{O}_{2} / \mathrm{N}_{2}$.

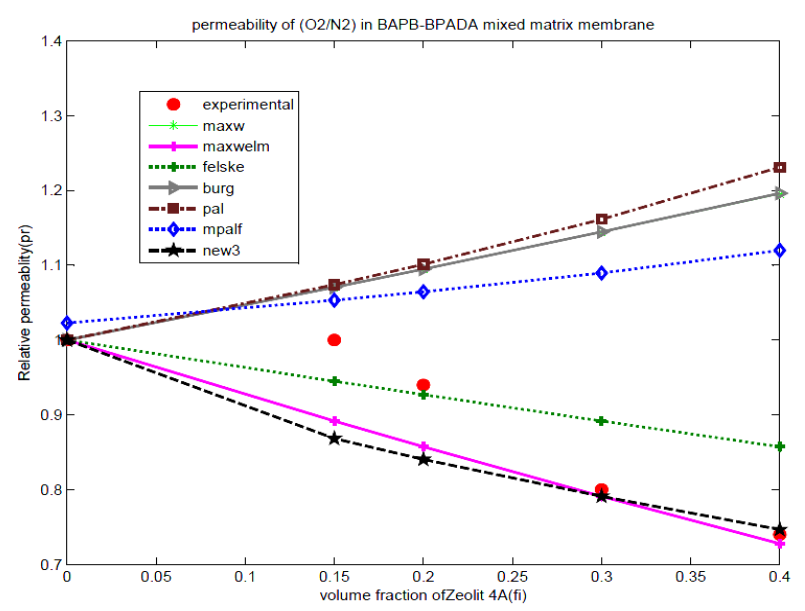

Fig. 6. Comparison of relative permeability of new model with existing models in system BAPB-BPADA /Zeolit4A for separation $\mathrm{O}_{2} / \mathrm{N}_{2}$ 


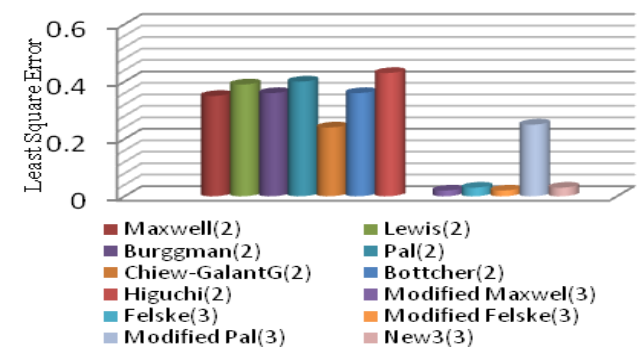

Fig. 7. Comparison between least square error of new proposed model with exising models of BAPB-BPADA/Zeolit4A system for separation $\mathrm{O}_{2} / \mathrm{N}_{2}$

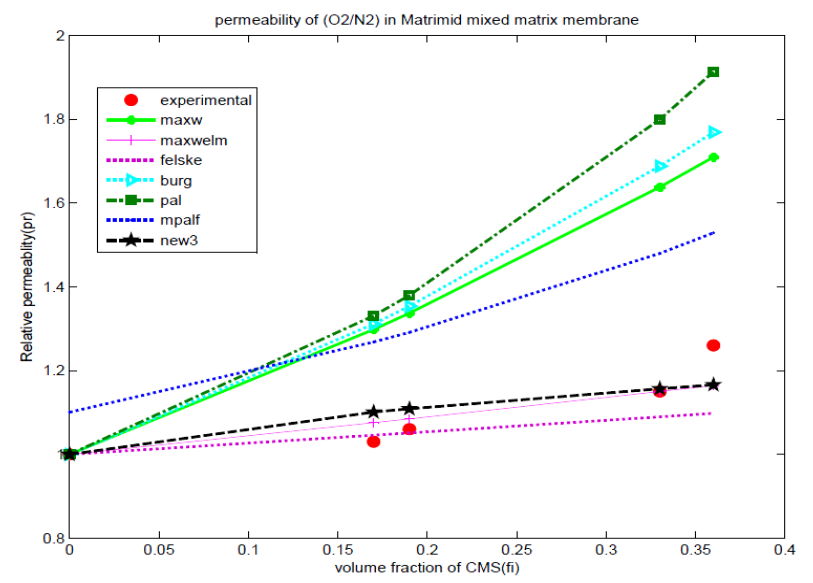

Fig. 8. Comparison of relative permeability of new model with existing models in system Matrimid /CMSfor separation $\mathrm{O}_{2} / \mathrm{N}_{2}$.

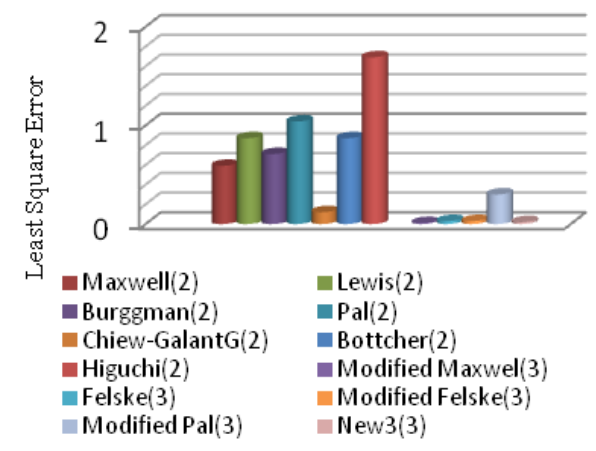

Fig. 9. Comparison between least square error of new proposed model with exising models of Matrimid /CMS for separation $\mathrm{O}_{2} / \mathrm{N}_{2}$.

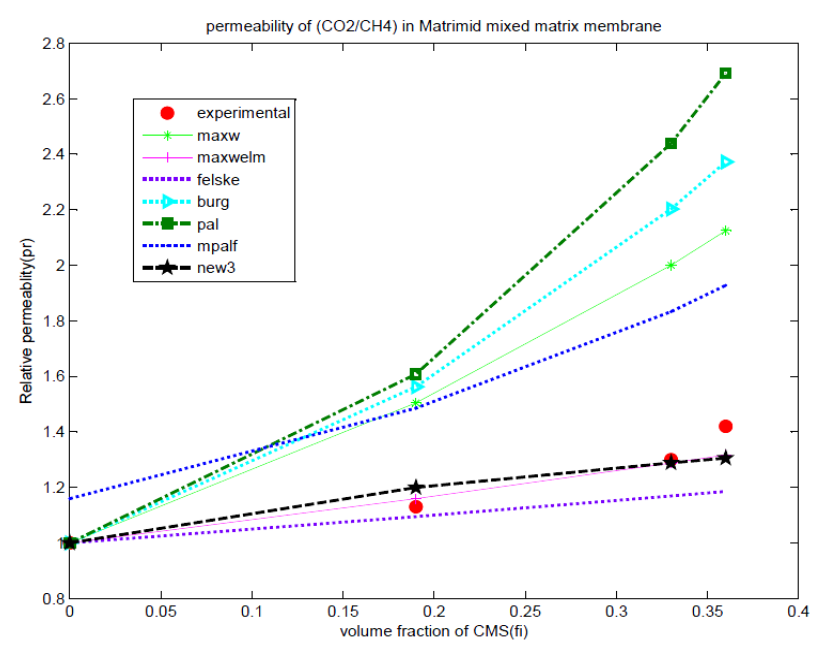

Fig. 10. Comparison of relative permeability of new model with existing models in system Matrimid /CMSfor separation $\mathrm{CO}_{2} / \mathrm{CH}_{4}$.

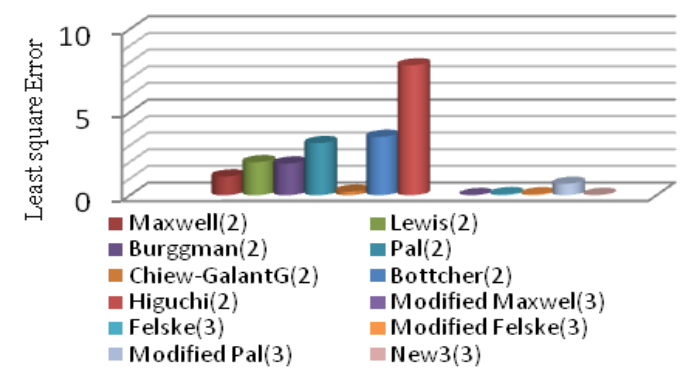

Fig. 11. Comparison between least square error of new proposed model with exising models of Matrimid /CMS for separation $\mathrm{O}_{2} / \mathrm{N}_{2}$

\section{CONCLUSiOnS}

In this paper, with proving equality of relative permeability of particle to polymer $\left(\lambda_{d m}\right)$ with equation $\beta / \gamma, \mathrm{a}$ developed model of Sing permeation model obtained for switching from two-phase models to three-phase models.

Regarding the results mentioned in pervious section, although new three-phase model improved based on felske thermal conductivity model, it predicts better than other three-phase permeation models; felske, modified felske and modified pal and as well as modified Maxwell.

Consideration of interfacial phase in developing Sing model apparently shows that this new proposed model can be another alternative to explain gas prediction through Mixed Matrix Membranes.

\section{REFERENCES}

[1] Y. Zhang, J. Sunarso, S. Liu, and R. Wang, "Current status and development of membranes for $\mathrm{CO}_{2} / \mathrm{CH}_{4}$ separation: A review," International Journal of Greenhouse Gas Control, vol. 12, pp. 84-107, 2013.

[2] H. V. Thang and S. Kaliaguine, "Predictive models for mixed-matrix membrane performance: A review," ACS Publications, vol. 113, no. 7, pp. 4980-5028, 2012.

[3] R. H. Perry and D. H. Green, Perry's Chemical Engineers' Handbook, 7th edition, McGraw-Hill, 1997.

[4] J. Leos, Zydney, and L. Andrew, "Microfiltration and Ultrafitration," Principles and Applications, New York: Marcel Dekker, Inc, 1996.

[5] T. S. Chung, L. Y. Jiang, Y. Li, and S. Kulprathipanja, "Mixed matrix membranes (MMMs) comprising organic polymers with dispersed inorganic fillers for gas separation," Progress in Polymer Science, vol. 32, pp. 483-507, 2007.

[6] A. Bushell, "Mixed matrix membranes of a polymer of intrinsic micro porosity with crystalline porous solids," A thesis submitted to the University of Manchester, 2012.

[7] L. M. Robesson, "The upper bound revisited," Journal of Membrane Science, vol. 320, pp. 390-400, 2008.

[8] N. Mansouri et al., "Porosity, characterization and structural properties of natural zeolite-clinoptilolite - as a sorbent," Environment Protection Engineering, vol. 39, no. 1, pp. 139-153, 2013.

[9] D. Q. Vu, W. J. Koros, and S. J. Miller, "Mixed matrix membranes using carbon molecular sieves I. Preparation and experimental results," J. Membr. Sci., vol. 211, pp. 311-334, 2003.

[10] M. Sadrzadeh, E. Saljoughi, K. Shahidi, and T. Mohammadi, "Preparation and characterization of a composite PDMS membrane on CA support," Journal of Polymers for Advanced Technologies, vol. 21, pp. $568-577,2010$.

[11] S. A. Hashemifard, "A new theoretical gas permeability model using resistance modeling for mixed matrix membrane systems," Journal of Membrane Science, vol. 350, pp. 259-268, 2010.

[12] B. Shimekit et al., "Prediction of the relative permeability of gases in mixed matrix membranes," Journal of Membrane Science, vol. 373, pp. 152-159, 2011.

[13] K. M. Gheimasi, T. Mohammadi, and O. Bakhtiari, "Modification of ideal MMMs permeation prediction models: Effects of partial pore blockage and polymer chain rigidification," Journal of Membrane Science, vol. 427, pp. 399-410. 
[14] W. K. Chen, Linear Networks and Systems, Belmont, CA: Wadsworth, 1993, pp. 123-135, 2013.

[15] E. E. Gonzo, "Estimating models for predicting effective permeability of mixed matrix membranes," Journal of Membrane Science, vol. 277 , pp. 46-54, 2006.

[16] C. T. Shung, "Mixed matrix membranes (MMMs] comprising organic polymers with dispersed in organic fillers for gas separation," Prog. Polym. Sci., vol. 32, pp. 483-507, 2007.

[17] M. A. Aroon, A. F. Ismail, T. Matsuura, and M. M. M. Rahmati, "Performance studies of mixed matrix membranes for gas separation: a review," Sep. Purif. Technol., vol. 75, pp. 229-242, 2010.

[18] R. Pal, "Permeation models for mixed matrix membranes," Journal of Colloid and Interface Science, vol. 317, pp. 191-198, 2008.

[19] D. A. G. Bruggeman, "Berechnung verschiedener physikalischer Konstanten von heterogenen Substanzen," Ann. Phys. Leipzig Journal, vol. 24, pp. 636-679, 1935.

[20] C. J. F. Bottcher, "The dielectric constant of crystalline powders," Recueil des Travaux Chimiques des Pays-Bas 64, pp. 47-51, 1945.

[21] W. I. Higuchi and T. Higuchi, "Theoretical analysis of diffusion at movement through heterogeneous barriers," J. Amer. Pharm. Assoc., Sci. Ed., vol. 49, pp. 598-606, 1960.

[22] L. Nielsen, "Thermal conductivity of particulate-filled polymers," $J$. Appl. Polym. Sci., vol. 11, p. 3819, 1973.

[23] E. E. Gonzo, "Estimating correlations for the effective thermal conductivity of granular materials," Journal of Membrane Science, vol. 427, pp. 399-410, 2002.

[24] Y. C. Chiew and E. D. Glandt, "Effect of structure on the conductivity of a dispersion," J. Colloid and Interface Science, vol. 94, no. 1, pp. 90-104, 1983.

[25] J. D. Felske, "Effective thermal conductivity of composite spheres in a continuous medium with contact resistance," J. Heat and Mass Transfer, vol. 47, pp. 3453-3461, 2004.

[26] R. Singh and P. Sharma, "Effective thermal conductivity of polymer composites," J. Advanced Engineering Materials, vol. 10, no. 4, pp. 366-370, 2008

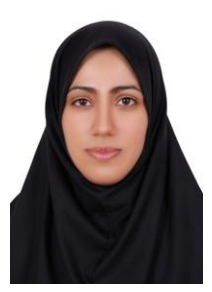

Z. Sadeghi was born in Tehran, Iran in 1979. She got her B.S. in chemical engineer from Isfahan University of Technology, Isfahan, Iran, 2003 and she is a student in last semester M.Sc. in chemical engineering of Islamic Azad University-Tehran North Branch, Tehran, Iran.

She is now a senior process engineer in TACECO (Tarh Andishan Consulting Engineering Company in field of oil, gas and petrochemical projects) and a senior process engineer in Karoon Petrochemical Complex
Plant. Her publications included "Modeling of mixed matrix membranes containing MOF-MIL-53 particles," Tehran, Iran, Civilika, 2014, "The effect of particle porosity in mixed matrix membrane permeation models," London, UK, ICCPE 2015 (submitted). In addition, Her main research areas are process and heat exchanger simulation and modeling, heat exchanger design.

Ms. Sadeghi became a member of IACHE (Iran Association of Chemical Engineers).

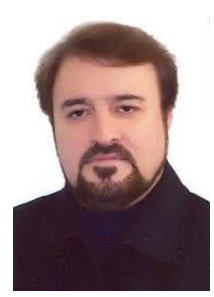

M. R. Omidkhah was born in Tehran, Iran in 1958. He got his B.Sc. degree in chemical engineering in 1982 from Amir Kabir University of Technology, Tehran, Iran. Also he got M.Sc.in chemical engineering in 1985 from Wayne State University of Michigan, USA and $\mathrm{Ph} . \mathrm{D}$. in the same field in 1990 from UMIST, Manchester, UK.

He is now the president of Chemistry and Chemical Engineering Research Center of Iran and a faculty member of Chemical Engineering Department in Tarbiat Modarres University.

Professor Omidkhah is the chairman of the board of TPI (Technology Park of Iran), president of IAChE (Iranian Association of Chemical Engineering), and an advisor to the Minister of Industry, a consultant to National Iranian Petrochemical Company (NIPC) and National Iranian Oil Company (NIOC).

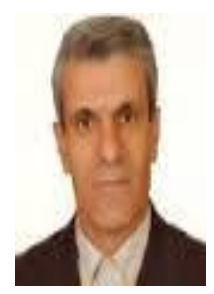

M. E. Masoumi was born in shabestar, Iran in 1966 . He got his B.Sc. degree in chemical engineering in 1990 from Sharif University of Technology in Tehran, Iran Also he got M.Sc. and Ph.D. in the same field in 1994 and 2003 from Tarbiat Modarres University in Tehran, Iran.

He had two summer fellowship in Tabriz and Tehran refineries. Now he is a faculty member and the head of Chemical Engineering Department in Islamic Azad University, Tehran North Branch.

Dr. Masoumi is a member of IAChE (Iran Association of Chemical Engineers) and IACSIT (International Association of Computer Science and Information Technology). 